Review

\title{
Plant Products for Pharmacology: Application of Enzymes in Their Transformations
}

\author{
Marie Zarevúcka ${ }^{1}$ and Zdeněk Wimmer ${ }^{2, *}$
}

1 Institute of Organic Chemistry and Biochemistry, AS CR, Flemingovo náměstí 2, 16610 Prague 6 - Dejvice, Czech Republic. E-Mail: zarevucka@uochb.cas.cz

2 Institute of Experimental Botany AS CR, Isotope Laboratory, Vídeňská 1083, 14220

Prague 4 - Krč, Czech Republic

* Author to whom correspondence should be addressed; E-Mail: wimmer@biomed.cas.cz; Tel. +420-241-062-457; Fax: +420-241-062-150

Received: 7 November 2008; in revised form: 24 November 2008 / Accepted: 3 December 2008 / Published: 4 December 2008

\begin{abstract}
Different plant products have been subjected to detailed investigations due to their increasing importance for improving human health. Plants are sources of many groups of natural products, of which large number of new compounds has already displayed their high impact in human medicine. This review deals with the natural products which may be found dissolved in lipid phase (phytosterols, vitamins etc.). Often subsequent convenient transformation of natural products may further improve the pharmacological properties of new potential medicaments based on natural products. To respect basic principles of sustainable and green procedures, enzymes are often employed as efficient natural catalysts in such plant product transformations. Transformations of lipids and other natural products under the conditions of enzyme catalysis show increasing importance in environmentally safe and sustainable production of pharmacologically important compounds. In this review, attention is focused on lipases, efficient and convenient biocatalysts for the enantio- and regioselective formation / hydrolysis of ester bond in a wide variety of both natural and unnatural substrates, including plant products, eg. plant oils and other natural lipid phase compounds. The application of enzymes for preparation of acylglycerols and transformation of other natural products provides big advantage in comparison with employing of conventional chemical methods: Increased selectivity, higher product purity and quality, energy conservation, elimination of heavy metal catalysts, and sustainability of the employed
\end{abstract}


processes, which are catalyzed by enzymes. Two general procedures are used in the transformation of lipid-like natural products: (a) Hydrolysis/alcoholysis of triacylglycerols and (b) esterification of glycerol. The reactions can be performed under conventional conditions or in supercritical fluids/ionic liquids. Enzyme-catalyzed reactions in supercritical fluids combine the advantages of biocatalysts (substrate specificity under mild reaction conditions) and supercritical fluids (high mass-transfer rate, easy separation of reaction products from the solvent, environmental benefits based on excluding organic solvents from the production process).

Keywords: Lipase; hydrolysis; esterification; plant oil; phytosterol; supercritical fluid; ionic liquid.

\section{Introduction}

Plant products with low polarity are mainly understood to be represented by plant lipids, formed by glycerides, important sources of fatty acids (FAs), and by compounds soluble in lipid phase (phytosterols, vitamins etc.). Glycerides are important natural and sustainable sources of FAs. Among them, $\omega-3$ and $\omega-6$ polyunsaturated fatty acids (PUFAs) belong among the main FA classes, derived biosynthetically from linoleic acid (LA) (Scheme 1). LA and ALA are termed essential fatty acids (EFAs) because mammalian cells are unable to synthesize these compounds de novo. LA can be converted sequentially by the known biosynthetic pathways into the $\mathrm{C}_{18} \omega-3$ and $\omega-6$ fatty acids, $\alpha$ linolenic acid (ALA) and $\gamma$-linolenic acid (GLA), and into the $\mathrm{C}_{20}$ - arachidonic acid (AA) and dihomo- $\gamma$-linolenic acid (DGLA). ALA is converted into longer chain $\omega-3$ fatty acids, such as $\mathrm{C}_{20}-$ icosapentaenoic (eicosapentaenoic) acid (EPA) and $\mathrm{C}_{22}$ - docosahexaenoic acid (DHA). Increasing evidence indicates that even if LA and ALA can be converted into their longer chain length metabolites, the conversion rate in humans is very slow, resulting in an estimated 2 to $10 \%$ of ALA being converted to DHA or EPA, and may be negatively affected by increasing age and any health injury [1,2]. This finding is a basis for a general suggestion that EFAs are likely to be dietary additives. This view may be supported by the experimental data on elevation of the cellular levels of both these $\omega-3$ PUFAs after supplying fish oil to humans [3]. $\omega-3$ PUFAs are of particular interest from a nutritional standpoint since the intake of these fatty acids is considered to be low in Western diets [4]. They have been investigated for their cardioprotective and anti-inflammatory roles, a treatment of certain forms of mental illness and as major targets of psychoactive medications, which has resulted in suggesting their increase as dietary supplements [5-9]. PUFAs may be directly administered as free fatty acids (FFAs), ethyl esters (FAEEs) or triacylglycerols (TAG). FFAs seem to be the best absorbable pharmaceutical form for preventing cardiovascular diseases [10] and FAEEs are used for treating pancreatic cancer cachexia (associated chronic weight loss) [11]. 
Scheme 1. Metabolic pathways of polyunsaturated fatty acids.

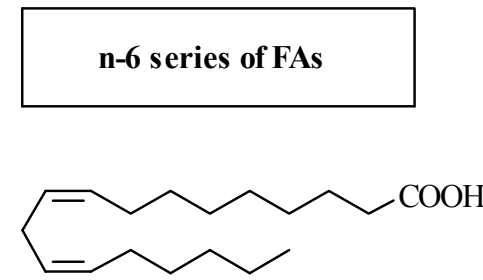

linoleic acid (LA, 18:2n-6)
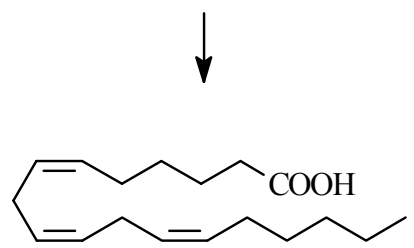

$\gamma$-linolenic acid (GLA, 18:3n-6)
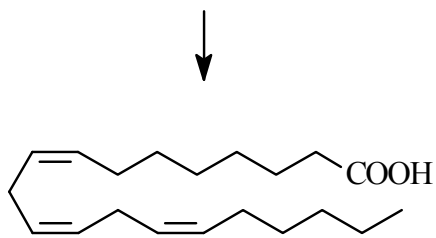

dihomo- $\gamma$-linolenic acid (DGLA, 20:3n-6)

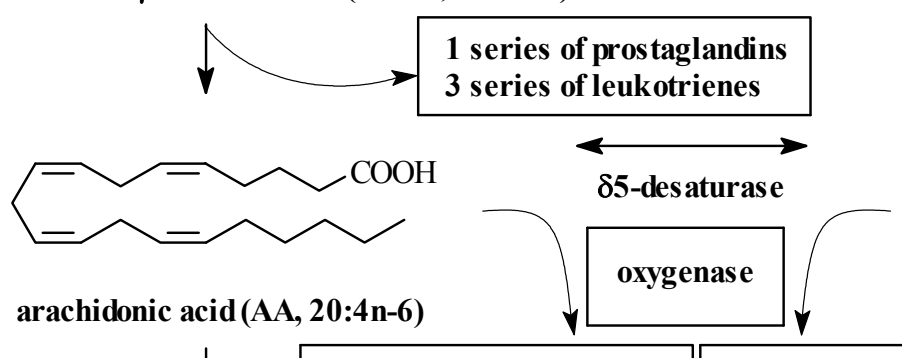

1 series of prostaglandin

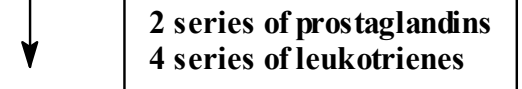

2 series of prostaglandins 4 series of leukotrienes<smiles>CCCCCC/C=C\C/C=C\C/C=C\C/C=C\CCCCC(=O)O</smiles>

adrenic acid (ADA, 22:4n-6)

\section{n-3 series of FAs}

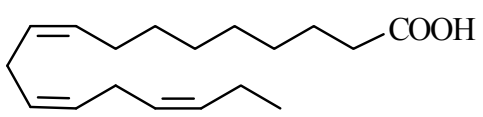

$\alpha$-linolenic acid (ALA, 18:3n-3)
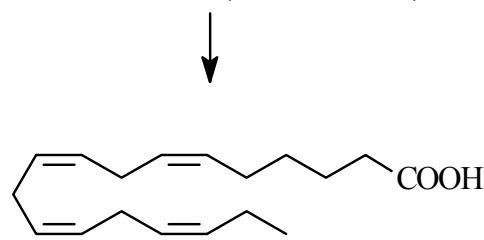

stearidonic acid (SA, 18:4n-3)

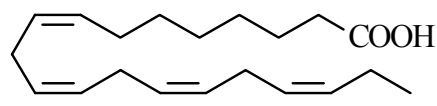

icos atetraenic acid (ITA, 20:4n-3)

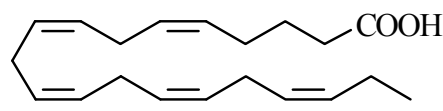

icos apentaenoic acid (IPA, 20:5n-3)

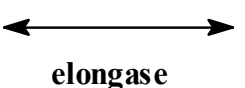

longase

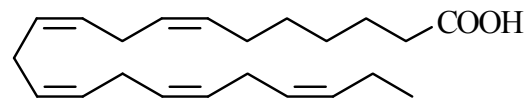

docos apentaenoic acid (DPA, 22:5n-3)

\section{PUFA Sources}

Natural sources of n-6 PUFAs contain variable amounts of these acids rarely exceeding 25\% GLA. Oils produced from borage, evening primrose and blackcurrant seeds are rich sources of GLA and contain $17-25 \%, 8-10 \%$ and $10-12 \%$ GLA, respectively [12-14]. Thus, there has always been a pharmacologically motivated increasing interest in producing higher concentrates of GLA. Different techniques have been developed to enrich GLA from natural sources, and they include urea fractionation of FAs [15-17], separation on Y-zeolite and lipase-catalyzed reactions, namely selective hydrolysis of GLA-containing triacylglycerols [18], and selective esterification of GLA-containing FA mixtures [19]. The only commercial sources of n-3 PUFAs (EPA and DHA) and AA are fish oils and animal viscera [20, 21]. However, many microalgae species, including krill, have also been found to be 
rich in oils containing various amounts of PUFAs [22-25]. Marine fish oils contain substantial amounts of PUFAs, and are currently the major sources of EPA and DHA [26]. Many plant sources are composed of essential long-chain fatty acids (LCFAs) such as oleic acid (C18:1), linoleic acid (C18:2) and linolenic acid (C18:3). Palm olein fractions contain a high proportion of unsaturated fatty acids, in particular C18:1 (63.1\%) and C18:2 (23.9\%) [27]. These LCFAs are generally recognized as useful nutrient substrates.

\section{Triacylglycerol structure}

In nearly all plant cells, energy reserves in the forms of FAs are contained in a triacylglycerol molecule. Since the glycerol molecule does not have rotational symmetry, all the carbon atoms distinguish from each other. They are classified by the $s n$ (stereochemical numbering) system (sn-1, sn-2, and sn-3; Figure 1) according to the recommendation of the IUPAC-IUB Commission of Biochemical Nomenclature. The plant triacylglycerols can posses a great number of different fatty acids, although eight particular ones account for some $97 \%$ of those present in commercial vegetable oils. The seed triacylglycerols are usually characterized by predominance of $\mathrm{C}_{18}$-unsaturated acids and PUFAs, and this distinguishes them from animal fats, which are generally of a more saturated nature. The $\mathrm{C}_{18}$-unsaturated fatty acids (oleic, linoleic, and linolenic) are particularly important and govern, to a large degree, the physical properties of the oils, and hence their practical applications and commercial values. The particular FAs in the plant TAGs are not distributed randomly between the different sn-positions [28, 29].

Figure 1. Triacylglycetol structure, $R=$ fatty acid acyl chains.

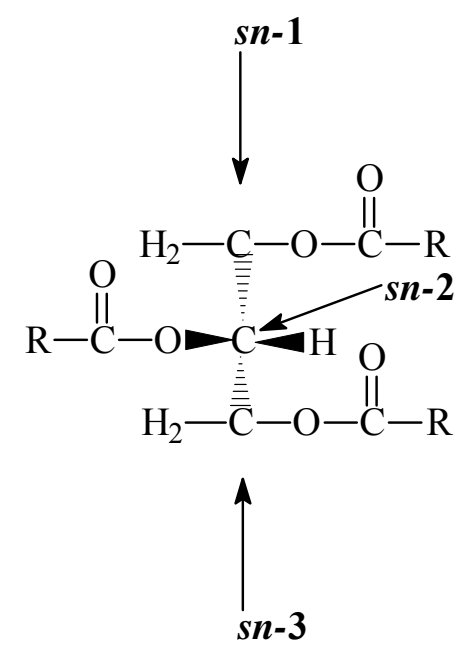

\section{Enzymes acting in lipid modifications}

Oils and fats have belonged among the most important renewable materials for the chemical industry. Industrial oleochemistry has concentrated predominantly on reactions involving carboxylate functionalities of the fatty acids. Modern synthetic methods have been extensively applied to all types of natural FA derivatives for the selective functionalization of their alkyl chains [30]. Application of 
enzymes acting in lipid modifications displays increasing role among those methods, especially when the products are considered for application in pharmacology or in food industry [31].

Hydrolysis of plant oils has been an important reaction for the production of fatty acids and glycerol as a major source of surfactants and detergents. Another process of industrial importance has been the hydrolysis of vegetable oils to enrich them with FFAs [32-34], especially PUFAs, which have been of considerable pharmaceutical interest due to their biomedical properties. A replacement of the present chemical processes has been strongly required, because high temperature, high pressure and presence of inorganic catalysts are involved in the hydrolysis of oil [35]. The environmentally friendly and sustainable alternatives are enzyme-catalyzed processes. The mild temperature conditions required for enzymatic hydrolysis allow energy saving and lead to a product of improved quality (color and flavor) free of traces of inorganic catalysts. Lipases and other less frequently used enzymes acting in lipid modifications (lipoxygenases and phospholipases) can selectively lower activation energies, provide higher reaction specificities and enhance reaction rates in comparison to non-enzymatic reactions [36]. The enzyme-catalyzed hydrolysis can be performed in aqueous, organic or other non-conventional reaction media, e.g. supercritical fluids, ionic liquids and their combinations [37]. While organic solvents affect the nature of biocatalysis in several ways, including interaction with the essential hydration level of the enzyme, direct participation in the reaction mechanism, alteration of protein structure and its flexibility and alteration of the observed enzyme kinetics [38], supercritical fluids and ionic liquids represent environmentally friendly media for enzyme catalyzed processes [37, 39].

Scheme 2. Lipase-catalyzed reversible process of a triacylglycerol hydrolysis and formation.

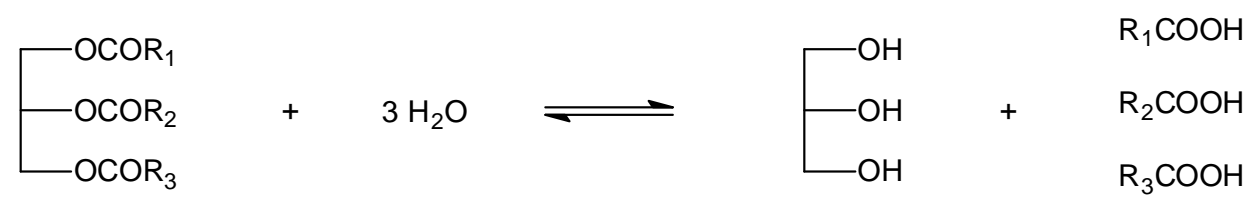

\subsection{Lipases}

Lipases (triacylglycerol hydrolases; E.C.3.1.1.3) belong to the family of serine hydrolases and can be found in animals, plants, fungi and bacteria [40-43]. They can also catalyze the formation of acylglycerols from FFAs and glycerol because the reaction they catalyze is reversible (Scheme 2). In the industrially developed countries, lipids present in the human diet mainly consist of triacylglycerols (TAGs), from 100 to about $150 \mathrm{~g}$ per day, i.e., 30\% of each individual's daily caloric intake. However, these TAG molecules cannot cross the intestinal barrier. A series of hydrolytic and absorption stages are necessary to produce the chemical energy resources present in the hydrocarbon chains of biologically usable TAGs. Lipases in the digestive tract play an important role in nutrition processes, both in humans and in higher animals [44]. Some lipases are able to control access to their active site. However, most of the lipases, which are used in laboratory investigations and/or in industrial production, are substrate tolerant enzymes, which accept a large variety of natural and synthetic substrates for biotransformation. Lipases do not require cofactors. They are often used in both, free or immobilized forms, and are commercially available, relatively inexpensive, and display relatively high stability. They act at the lipid-water interface and, therefore, they do not require water-soluble 
substrates. This function distinguishes lipases from other hydrolytic enzymes, and their efficiency in conducting transformations in organic solvents under mild conditions increases their importance as useful tools in organic synthesis [40-43,45-48]. Reactions in which lipases may be involved, both in nature and in laboratory or industrial application, are: (a) enzyme-catalyzed hydrolysis, (b) enzymecatalyzed esterification, (c) enzyme-catalyzed transesterification by acidolysis, (d) enzyme-catalyzed transesterification by alcoholysis, (e) enzyme-catalyzed interesterification and (f) enzyme-catalyzed aminolysis (Scheme 3).

Scheme 3. Processes catalyzed by lipases: (a) enzyme-catalyzed hydrolysis, (b) enzymecatalyzed esterification, (c) enzyme-catalyzed transesterification by acidolysis, (d) enzymecatalyzed transesterification by alcoholysis, (e) enzyme-catalyzed interesterification and (f) enzyme-catalyzed aminolysis.<smiles>[R]C(=O)O[Na]</smiles><smiles>[R]C(=O)O</smiles>

$\mathrm{R}_{2} \mathrm{OH}$

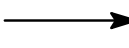<smiles>[R]OC(=O)CCCCC</smiles><smiles>[R]C(=O)OC</smiles><smiles>[R]OC([R])=O</smiles>

$\mathrm{R}_{3} \mathrm{OH}$<smiles>[CH]C</smiles><smiles>[R]OC([R])=O</smiles><smiles>[R]OC([R])=O</smiles><smiles>[111IH]</smiles><smiles>[R]OC([R])=O</smiles><smiles>[R9]NC([R])=O</smiles>

(e)

(a)

(b)

Lipase-catalyzed reactions are carried out under mild conditions: temperature lower than $70{ }^{\circ} \mathrm{C}$, atmospheric pressure and with higher selectivity than their chemical counter parts. These enzymes catalyze the hydrolysis of glycerides at oil-water interfaces in vivo. In organic media with low water activity, they catalyze esterification [49] and interesterification of TAGs via alcoholysis, acidolysis, and transesterification [50-75]. Most of these works are kinetic studies on model reactions of 
acidolysis [53, 59, 60, 63-65] at lab-scale, and frequently in the presence of organic solvents [53-56, 63]. The bioproduction of TAGs enriched with $\omega$-3 PUFAs has also been attempted via acidolysis [6673]. In these systems, the recovery of the modified TAGs is rather difficult. Therefore, for industrial purposes, lipase-catalyzed transesterification-ester interchange, seems to be a more adequate route than acidolysis $[51,55-57,74,75]$. The fats were obtained by transesterification of palm oil stearin with a concentrate of TAGs enriched with $\omega-3$ PUFAs and soybean oil, catalyzed by a commercial immobilized Candida antarctica lipase (Novozyme 435) in solvent-free media.

Lipases occur widely in animals, plants and microorganisms [76]. One attractive feature of lipases is their specificity with respect to the glyceride position and fatty acid type, which could seldom be constructed by chemical catalysis [77]. Although a number of lipases, especially those in microorganisms, have been well characterized, knowledge of their structure-activity relationships remains sparse [78]. Lipase-catalyzed reactions offer several benefits over chemically-catalyzed reactions, such as milder operation conditions [79].

\subsection{Lipase structure and catalytic ability}

A mobile element, known as "lid", consisting of either one or two short $\alpha$-helices linked to the body of the lipase by flexible structural elements is present in most of lipases. In the open active site of lipases, the lid moves away making the binding site accessible to the substrate [80]. On the other hand, the lid needs an interface to be opened [81-85]. Three types of lipases could be identified according to their coordination-substrate site [86]: (a) Lipases corresponding to the Rhizomucor family including Thermomyces (formerly Humicola) lanuginosa, which have active sites and lids on the surface of the enzymes; (b) Lipases corresponding to the Pseudomonas and Candida antarctica family, which have active sites and funnel-like lids. Candida antarctica lipase B exhibits a very small lid and a funnel-like binding site; (c) Lipases corresponding to the Candida rugosa family, characterized by the presence of active sites at the ends of tunnels containing the lids in their external parts [87]. This peculiarity affects the coordination of the substrate because the reaction catalyzed by $R$. miehei is stimulated in either positions $s n-1$ or $s n-3$ - rather than in the position $s n-2$ - of the triglyceride, whereas in C. rugosa the serine, which is a part of the catalytic triad of the lipase, attacks all positions of the triglyceride [84].

\subsection{Lipase-catalyzed hydrolysis under conventional conditions}

Different lipases show different specificity, which is the cleavage of various bonds, chain length and structures of the cleaved fatty acids. Bottino et al. [88] noted that pancreatic lipase shows less activity towards icosapentaenoic acid and docosahexaenoic acid. They attributed the resistance to the location of a Z-configured double bond near the esterified carboxyl group or to the presence of several $Z$-configured double bonds in the chain placing the terminal methyl group in a position near the ester bond, thereby causing steric hindrance. Jensen et al. [89] reported that 15 triacylglycerols containing double bonds at various positions were hydrolyzed by pancreatic lipase. The substrates containing the $\Delta^{2}$ through $\Delta^{7}$ isomers of octadecaenoic acid were resistant to pancreatic lipolysis. The discrimination was greatest against the $\Delta^{5}$ isomer in the octadecaenoic acid series, when the double bond is beyond $\mathrm{C}(7)$. Moreover, Geotrichum lipase exhibits a high degree of discrimination in favor of acids having a cis double bond at the $\Delta 9$ position [89]. However, Lopez-Martinez et al. [90] reported the hydrolysis 
of borage seed oil containing $\gamma$-linolenic acid $(6,9,12$-octadecatrienoic acid) using two kinds of microbial lipases: (a) When employing Candida cylindracea lipase for catalyzing hydrolysis of the borage oil, $\gamma$-linolenic acid was accumulated in the non-hydrolyzed glyceride residue due to the lipase specificity towards $\gamma$-linolenic acid exhibiting $\Delta 6$ unsaturation; (b) With the Chromobacterium viscosum lipase, no accumulation of $\gamma$-linolenic acid was observed. Using this resistance to fatty acids, when fish oil was partially hydrolyzed by the microbial lipases produced by C. cylindracea, A. niger or G. candidum, the content of $\omega-3$ polyunsaturated fatty acid in the remaining glycerides significantly increased [91, 92].

\subsection{Lipase-catalyzed reactions under non-conventional conditions}

Plant seed oils are one of the most important sustainable sources of FAs. Hydrolysis is the basic procedure of modification of natural triacylglycerols. Plant oils also contain certain quantities of additional natural products with pharmacological importance: vitamins, phytosterols, phytosteroids and other compounds. They are mainly isolated from oilseeds during the deodorization process within the volatile by-product known as deodorizer distillate at a quantity between 2 and $20 \%$, together with FFAs, mono-, di- and triacylglycerols [93, 94]. Modern non-conventional media (supercritical fluids, ionic liquids or their combination) are nowadays applied in obtaining FFAs from plant seed oils and modifying their structure by subsequent enzyme-catalyzed transformations [31, 95-97].

\subsubsection{Properties of supercritical carbon dioxide}

Supercritical fluids have unique properties, which can be applied to a wide range of novel chemical processes [98-103]. Among them, supercritical carbon dioxide, defined as carbon dioxide above its critical point $\left(t_{c}=31.3{ }^{\circ} \mathrm{C}, \mathrm{P}_{\mathrm{c}}=7.4 \mathrm{MPa}\right)$, has the added benefits of an environmentally benign nature, non-flammability, low toxicity and ready availability, and it exhibits similar properties to organic solvents. It differs from ordinary solvents in having a combination of gas-like properties (i.e. low viscosities and high diffusivities which make them favorable for mass transfer) and liquid-like properties (i.e., solubilizing power) [104], which are tunable by the manipulation of pressure and temperature. Small variations in pressure or temperature lead to significant changes in density and density-dependent solvent properties such as dielectric constant, solubility parameters and partition coefficient, and render them more attractive as 'green designer' solvents and promising reaction media for environmentally benign chemical processes [104]. A scheme of the system used for extractions and enzyme-catalyzed processes operated under supercritical conditions is shown in Figure 2.

\subsubsection{Properties of ionic liquids}

Ionic liquids are substances composed entirely of ions [105-107]. They are relatively polar solvents and promote the dissolution of a vast array of pharmaceutical intermediates and final drug molecules $[108,109]$. The ability to modify the physico-chemical properties of these substances by simple structural modifications to the cations or changes in the anions increases the importance of ionic liquids in organic chemistry [105, 108, 110-112]. 
Figure 2. System for performing enzyme-catalyzed reactions in supercritical carbon dioxide: (1) compressor, (2) pressure control unit, (3) and (4) optional mixing or saturation units, (5) reactor, (6) oven, (7) rinsing valve, (8) micrometer valve, (9) trap, (10) gas meter.

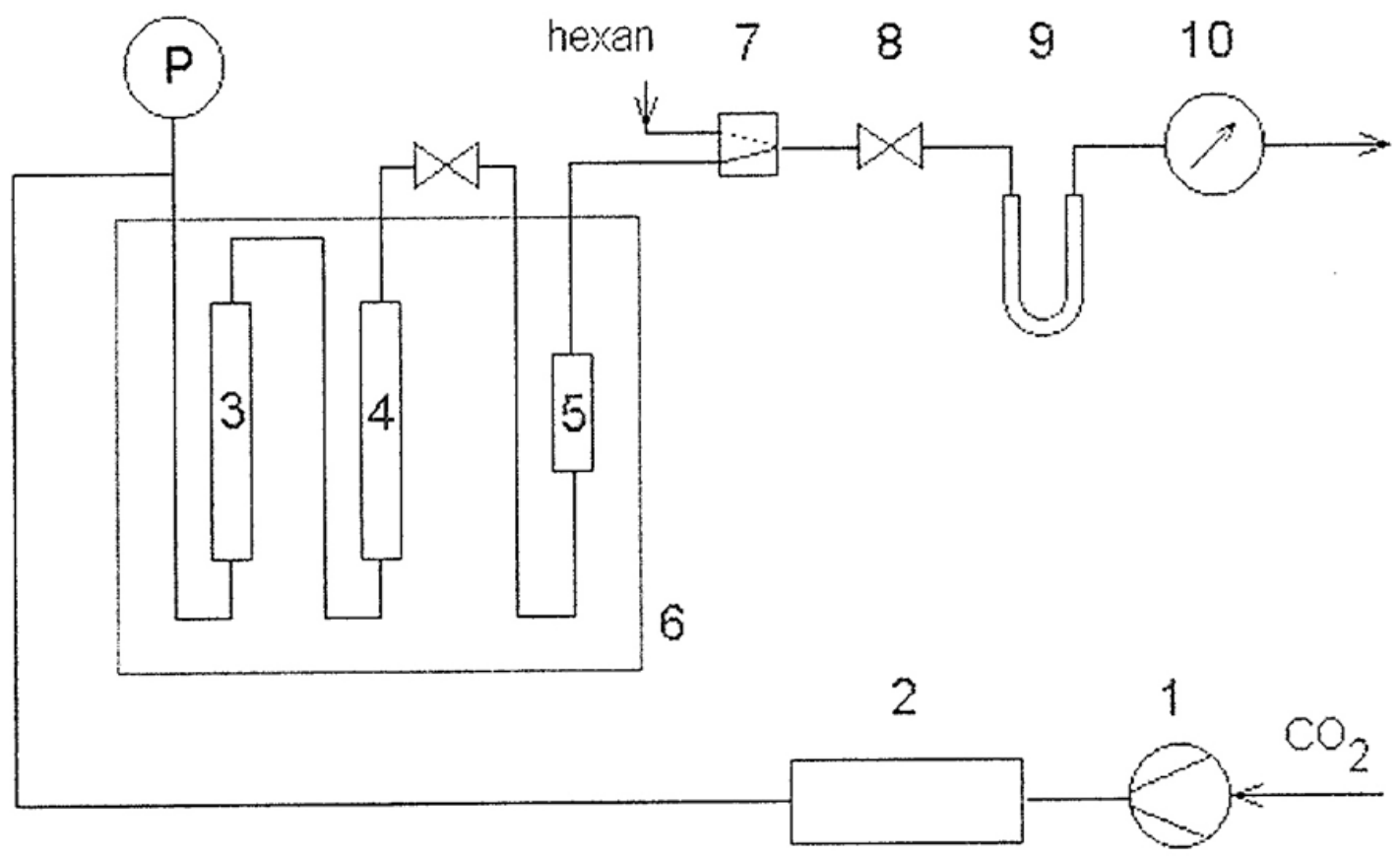

\subsubsection{Lipase-catalyzed hydrolysis in supercritical carbon dioxide}

The application of supercritical carbon dioxide as a solvent in enzyme-catalyzed reactions has been a matter of considerable research because of its favorable transport properties, which accelerate masstransfer-limited enzymatic reactions [113]. The inherent gas-like low viscosities and high diffusivities of supercritical fluids increase the rates of mass transfer of substrates to the enzyme. Conversely, the liquid-like densities of supercritical fluids result in higher dissolution compared to those observed for gases. Unlike the behavior of gases and liquids, the physical properties of supercritical fluids can be adjusted over a wide range by a relatively small change in pressure or temperature [114]. Moreover, it might be relevant to stress much lower expenses of solvent in the supercritical medium compared with those of conventional solvents [35]. Another advantage of the use of supercritical fluids (gases) as reaction media is the simple separation of oil and water in a continuously operated reactor on an industrial scale, due to their different solubility in these media. Since the solvent strength of a supercritical fluid can be varied by changing pressure and temperature, the solubility of substances can easily be regulated. It can be done continuously at the outlet of the reactor, allowing an integrated reaction and separation step, and thus simplifying the downstream processing and recycling of the solvent [35].

Examples of industrially important hydrolytic processes catalyzed by lipases are productions of soaps [43,115], fatty alcohols [43] and monoacylglycerols [116,117]. Knez et al. [118] studied the thermodynamic and kinetic properties of the immobilized lipase from Aspergillus niger (Lipolase $100 \mathrm{~T}$ ), and used this enzyme for catalysis of hydrolysis of sunflower oil in supercritical carbon dioxide. Employing a high-pressure continuous flat-shape membrane reactor, they achieved maximum 
conversion after 1 hour of the reaction at $50{ }^{\circ} \mathrm{C}, 90 \mathrm{MPa}$, and at a flow rate for substrates of 0.1 $\mathrm{mL} / \mathrm{min}$, improved during following investigation $[119,120]$.

We have studied blackcurrant seed oil, which is rich in $\alpha$ - and $\gamma$-linolenic acid, which the human organism is unable to synthesize de novo [121]. To be able to isolate $\alpha$ - and $\gamma$-linolenic acid from blackcurrant seed oil, we used Lipozyme, a lipase from Mucor miehei, immobilized on macroporous anionic resin $[122,123]$. The reaction was performed in a continuous flow reactor at 10-28 $\mathrm{MPa}$ and $30-50{ }^{\circ} \mathrm{C}$ with carbon dioxide saturated with oil and water $(55-100 \%)$ flowing up through the enzyme bed. Analysis of product composition indicated unfavorable hydrodynamics with significant mixing in the reactor when solvent interstitial velocity was lower than $4 \mathrm{~cm} / \mathrm{min}$, while above this velocity value the flow pattern was near to plug flow. Lipase stability was very good with no activity reduction observed during a long-term experiment. The reaction rate was a function of the ratio of enzyme load to solvent volumetric flow rate. A complete hydrolysis of oil was achieved in the experiments carried out with the enzyme load of $0.8 \mathrm{~g}$ and $\mathrm{CO}_{2}$ flow rate of $0.4-0.9 \mathrm{~g} / \mathrm{min}$. The effects of pressure $(10-25$ $\mathrm{MPa})$ and temperature $\left(30-40{ }^{\circ} \mathrm{C}\right)$ on the reaction rate were small, and the effects of $\mathrm{CO}_{2}$ saturation with water and of enzyme distribution in the reactor were negligible. Lipozyme displayed specificity towards linolenic acids; the release of $\alpha$-linolenic acid was faster and that of $\gamma$-linolenic acid slower than the release of other constituent acids present in blackcurrant oil. The experimental system was also studied and analyzed by means of HPLC-NMR hyphenated technique [124].

\subsection{Lipase-catalyzed esterification in organic solvents}

Many lipases catalyze esterification reactions in organic solvents. TAG synthesis from DHA ethyl ester has been performed using the lipase from Candida antarctica immobilized on macroporous acrylic resin in a yield $>95 \%$ at $50^{\circ} \mathrm{C}$ for $23 \mathrm{~h}$ [125]. Not only plants are rich sources of PUFAs. For instance, the esterification of glycerol and $\omega$-3 PUFAs from cod liver oil was studied using Lipozyme IM from Mucor miehei, Novozym 435 from C. antarctica and lipase PS from Pseudomonas [126]. Novozym 435 has been proven to be highly active. Medina et al. [127] studied the production of commercially viable EPA-rich TAG from cod liver oil and the microalga $P$. tricornutum and TAG rich in EPA and AA from the microalga P. cruentum by esterification of these PUFAs with glycerol by lipase-catalyzed reactions.

\subsection{Lipase-catalyzed transesterification and acidolysis under conventional conditions}

Enzyme-catalyzed transesterification reactions have been employed for modification of fats and oils. The process involves rearrangement of fatty acid moieties within triacylglycerol molecules, with consequent improvement of the physico-chemical characteristics of fats and oils. Lipases have been used as biocatalysts for the modification of fatty acid profile of vegetable and marine oils to produce structured lipids, which are currently manufactured for their potential clinical benefits and for food applications. These nutraceutical lipids may provide specific fatty acids with particular properties desirable in specific disease or pathological conditions. A number of studies have focused on obtaining TAG having a combination of $\omega-3$ and $\omega-6$ PUFAs.

Senanayake and Shahidi [13] tested nonspecific C. antarctica, sn-1,3 specific M. miehei, and nonspecific Pseudomonas sp., which were able to catalyze incorporation of EPA and DHA in the 
borage and evening primrose oils to various extents. Among the lipases tested, Pseudomonas sp. gave the highest degree of EPA and DHA incorporation in both oils (32.6 and 32.3\% after $36 \mathrm{~h}$, in borage and evening primrose oils, respectively) followed by $M$. miehei and C. antarctica. The most effective lipase was selected for subsequent experiments to determine optimal acidolysis conditions. Previously, Akoh and Moussata [128] used two immobilized lipases, nonspecific SP435 from C. antarctica and sn-1,3 specific IM60 from Rhizomucor miehei as biocatalysts for restructuring of borage oil to incorporate EPA and capric acid (10:0) with free fatty acids as acyl donors. They obtained higher incorporation of EPA (10.2\%) and capric acid (26.3\%) using IM60 lipase, compared to 8.8 and 15.5\%, respectively, when SP435 lipase was used. The ability of immobilized lipases IM60 from M. miehei and SP435 from C. antarctica to modify the fatty acid composition of selected vegetable oils (canola, peanut, and soybean oils) by incorporation of $\omega$-3 PUFAs into the vegetable oils was studied [69] by using FFAs and FAEEs of EPA and DHA as acyl donors. Using free EPA as acyl donor, IM60 gave higher incorporation of EPA than SP435. However, with FAEEs of EPA and DHA used as acyl donors, SP435 gave higher incorporation of EPA and DHA than IM60.

\subsection{Structured lipids}

Structured lipids (SLs) are triacylglycerols or phospholipids in which FAs can be found in specific locations in the glycerol backbone and are produced using chemical or enzymatic processes. SLs are new generation fats or oils with medical, nutraceutical and food applications. Lipids can be restructured to meet EFA requirements or to incorporate specific FAs of interest into specific locations of the glycerol backbone of TAG. SL may offer the most efficient means of delivering target FAs for nutritive or therapeutic purposes as well as to alleviate specific disease and metabolic conditions.

The constituent FAs and their locations in the glycerol backbone determine the functional and physical features, the metabolic fate, and the health benefits of SLs. Therefore, designing SLs with selected FAs at specific locations in the TAGs for medicinal applications has attracted much attention. The position of FA in the TAG molecules (sn-1, sn-2, and sn-3) has a significant impact on their metabolism in the body. In general, FAs at the terminal positions of TAG (sn-1 and sn-3) are hydrolyzed by pancreatic lipase and absorbed, while those at the sn-2 position of TAG remain unchanged and are used in the synthesis of a new TAG. For example, it may be desirable to develop a SL containing PUFAs at the sn-2 position with medium-chain fatty acids (MCFAs) at the sn-1,3 positions for patients with mal-digestion as well as cystic fibrosis. A SL containing MCFA and linoleic acid is more efficient in cystic fibrosis patients than safflower oil, which has about twice as much of linoleic acid [129]. SLs have many industrial applications and have recently attracted the attention of food manufacturers for production of low-caloric lipids that are characterized by a mixture of short-chain fatty acids (SCFAs) and/or MCFAs and LCFAs in the same glycerol moiety. Increasing interest in such products stems from the fact that they contain $5-7 \mathrm{kcal} / \mathrm{g}$ energy compared to $9 \mathrm{kcal} / \mathrm{g}$ for usual fats and oils; this is because of the lower caloric content of SCFA or MCFA compared to LCFA. Reduced-calorie specialty lipids are intended for use in baking chips, dips, coatings, bakery and dairy products, or as a cocoa butter equivalent.

Over the past two decades several research groups have successfully incorporated MCFAs (caprylic acid or capric acid) into fish and marine oils containing PUFAs [72,128-133] into borage oil rich in $\gamma$ - 
linolenic acid [128, 130, 133] and into single-cell oils [134-137]. SLs may be produced by incorporation of selected FAs into an oil. The degree of reactivity of different FAs may vary in different systems due to factors such as the lipase type, water activity, and other conditions [138]. Many lipases have been shown to be more selective toward $\mathrm{C}_{18} \mathrm{FA}$ with higher degrees of unsaturation in esterification and interesterification reactions (C18:0 < C18:1 < C18:2) [139]. Yang et al. [138] compared incorporation of linoleic and conjugated linoleic (CLA) acids into tristearin (SSS) in a solvent-free system at $60{ }^{\circ} \mathrm{C}$ using 5\% Lipozyme RM IM from Rhizomucor miehei. Incorporation of LA into SSS was higher than that of CLA and suggested that the rigidity of CLA might have been responsible for this observation [138]. Tsuzuki [140] screened ten lipases for their ability to catalyze acidolysis of triolein with SCFAs (C2:0, C3:0, and C4:0) in organic solvents. Lipase from Aspergillus oryzae afforded the highest yields of products in the reaction of triolein with $\mathrm{C} 2: 0, \mathrm{C} 3: 0$, and $\mathrm{C} 4: 0$. The results of the study indicated that as the chain length decreased, the degree of incorporation of SCFAs into triolein increased. Paez et al. [141] reported that incorporation of caprylic acid (C8:0) into triolein was favored compared with that of oleic acid. Again chain length of the FA might play a role in the observed trends. The synthesis of a modified oil via acidolysis of trilinolein (tri C18:2) with C8:0, using Lipozyme IM-60 as a biocatalyst has been reported [142]. Lipozyme IM-60 was found to be more effective for incorporation of a LCFA than a MCFA. A synthesis of SL by interesterification of trilinolein and tricaproin with sn-1,3-specific (IM 60) and nonspecific (SP 435) lipases was reported [143]. In general, it was found incorporation of selected LCFAs into TAGs (e.g. tristearin or triolein) may be affected by many factors, including chain length, number of double bonds, and the location and geometry of the double bonds as well as reaction conditions and reactivity and specificity of lipases employed. LA was more reactive than CLA due to the rigidity of the latter and/or specificity of the enzymes [144]. EPA was more reactive than DHA, due to the structural differences between the two (number of double bonds, chain length) [145]. Lipases, Novozyme-435 enzyme from C. antarctica and AY-30 from Candida rugosa, might be considered as promising biocatalysts for acidolysis of tristearin and selected LCFAs [146]. The high percent incorporation of FA into tristearin using lipase from $C$. antarctica or C. rugosa might be due to the experimental conditions employed in the study which were suitable for these two enzymes [145]. Hamam and Shahidi [145] reported the acidolysis of tristearin and triolein [144] with LCFAs. In the study, they examined the effect of the chain length, number of double bonds, and the location and geometry of double bonds on the incorporation of selected FA into tri C18:2 and tri C18:3. Several studies have dealt with the synthesis of SL enriched in PUFAs using a one-step lipase catalyzed synthesis $[137,147,148]$. However, this synthesis required long reaction times and achieved only low yields of the desired products. The two-step reaction was recently suggested as an effective method for the SL synthesis resulting in higher yields and purer products than the conventional one-step reaction $[149,150]$. In the first-step, 2-MAG are produced by alcoholysis of a triglyceride with ethanol using a 1,3-regiospecific lipase. The 2-MAG thus obtained can subsequently be esterified with suitable FAs.

\subsubsection{Lipase-catalyzed esterification in supercritical carbon dioxide}

Lipase-catalyzed production of various types of esters, including SLs, has increased tremendously within the recent years. Esters are mainly present in oils, fats and natural polymers, and they are useful 
intermediates or target products in chemical industry. Acylglycerol and aliphatic ester synthesis by lipases was described [151, 152], and proved the occurrence of reverse reaction. Lipases from Aspergillus niger, Rhizopus delemar, Geotrichum candidum and Penicillium cyclopium catalyze the synthesis of oleic acid esters derived from a number of primary alcohols. Among these lipases, only that from G. candidum was able to catalyze the synthesis of esters of secondary alcohols. It can be achieved either by reaction between FFA and an alcohol or by ester exchange or transesterification, which includes alcoholysis, acidolysis and interesterification [45]. Lipase-catalyzed esterification reactions have been applied in a production of different types of important esters: (a) esters of shortchain alcohols and short-chain fatty acids (aroma compounds; [45]), (b) esters of short-chain alcohols and long-chain fatty acids (oleochemicals, e.g. lubricants, diesel fuel, and antistatic reagents; [45]), (c) esters of polyhydroxy alcohols (glycerol, alcoholic sugars, carbohydrates etc.) and long-chain fatty acids, which are generally called emulsifiers or surfactants (important products for application in food and pharmaceutical industries; [45]).

Lipases have often been used for treatment and modification of oils and fats [45]. Many lipases exhibit sn-1,3 specificity and may be used for regioselective (inter)esterification of natural triacylglycerols. The acyl migration observed from the $s n-2$ to the $s n-1$ or $s n-3$ positions must be suppressed or eliminated, wherever possible. By partial or total exchange of fatty acyls in TAGs of given origin it is possible to modify physico-chemical properties and also nutritional value of the starting natural oil or fat [45]. Three types of triacylglycerol modification are commercially and pharmacologically important: (a) production of cocoa butter equivalents, (b) production of fats with improved spreadability and (c) production of highly digestive triacylglycerols [43, 45].

(a) Cocoa butter equivalent: The main producers of cocoa butter are tropical countries, mainly Kenya and Malaysia. Since the melting point of cocoa butter is around human body temperature (37 ${ }^{\circ} \mathrm{C}$ ), it is well suited as a matrix for suppositories. The main application is in the production of chocolates, where the rapid melting conveys a desirable feeling. The predominant TAGs of cocoa butter are compounds bearing oleic acid in the $s n-2$ position and stearic and palmitic acids in the sn-1 and sn-3 positions (SOS and SOP). Cocoa butter equivalents can be prepared either chemically or by lipase catalysis through the interesterification of suitable natural triacylglycerols, for example, the middle fraction of palm oil (POP) or sunflower oil with a high content of oleic acid (high-oleic sunflower oil; OOO) with stearic acid or tristearin (SSS) [43,153]. The primary hydroxyl groups of glycerol in positions sn-1 and sn-3 are more reactive than the secondary hydroxyl group in the sn-2 position, and TAGs of the SOP or SOS type are predominantly formed.

(b) Fats with improved spreadability: The melting point of any oil can be modulated by the degree of catalytic hydrogenation of double bonds in unsaturated FAs, as it is done on a large scale for the preparation of margarines and shortenings from plant oils. Alternatively, the desired melting point can be achieved through interesterification of suitable triglyceride mixtures with the use of sn-1,3 specific lipases [43].

(c) Highly digestive triacylglycerols: The absorption of TAGs from the small intestine strongly depends on their structure. TAGs containing palmitic acid are well adsorbed only when this FA is located in the sn-2 position, like in human milk [154]. A commercial product of this type (OPO) is a diet additive for premature infants. It is prepared by interesterification of tripalmitin with oleic acid with use of immobilized Rhizomucor miehei lipase. Alternatively, TAGs of the MLM type, with long- 
chain saturated or unsaturated FAs (L) in the sn-2 position and medium-chain fatty acids (M) in the positions sn-1 and sn-3, provide a rapid delivery of energy through enhanced hydrolysis and resorption; pancreatic lipase preferentially hydrolyzes medium-chain triacylglycerols, and the resulting MAGs are efficiently absorbed from the large intestine. Several products of this type are commercially available, which contain PUFAs (EFAs), and have shown beneficial effects against cardiovascular and inflammatory diseases. Functional TAGs of this composition are preferentially prepared by means of sn1,3 specific lipases during an interesterification process starting from highly unsaturated TAGs [43].

\subsubsection{Other types of lipase-catalyzed reactions in supercritical carbon dioxide}

The utilization of supercritical carbon dioxide as a reaction medium confers many advantages, among which environmental compatibility, zero chemical residues in the synthesized product, and considerable processing flexibility are the most important [155]. When lipase is used for catalyzing a synthetic procedure in supercritical carbon dioxide, the process is particularly applicable to producing additives that can be incorporated directly into food formulations [45,156-161]. A synthesis of simple esters [162] was reported, transesterifications to make methyl esters [156] were conducted, a glycerolysis process [156] was studied, and randomization of fats/oils [156] in supercritical carbon dioxide was performed using Candida antarctica lipase (Novozym 435; [163]). High quantitative yields of transesterifications in making methyl esters have permitted application of the lipase reaction in supercritical carbon dioxide as an analytical method for quantifying fat levels in food products, required under new food nutritional labeling guidelines [164]. A Novozym 435-catalyzed transesterification has been utilized as the initial step in a two-stage synthesis conducted under supercritical fluid conditions to produce fatty alcohols directly from vegetable oils [165].

An interesting study has been performed with lipase-catalyzed esterification of stearic acid with ethanol, and subsequent hydrolysis of ethyl stearate under the conditions set near to the critical point in supercritical carbon dioxide ( $\mathrm{p}=6$ to $20 \mathrm{MPa}, \mathrm{t}=35$ to $60{ }^{\circ} \mathrm{C}$ ) [166], resulting in an observation of the esterification rate of stearic acid increasing near the critical point and keeping the increase steady with increasing the pressure, and reflecting the increasing solubility of stearic acid in supercritical medium. The hydrolysis rate of ethyl stearate showed its maximum at a pressure near the critical point, and it was dependent on the initial concentration of ethyl stearate in the system. When the reaction was performed with an initial ester concentration below the solubility limit in supercritical carbon dioxide, the authors observed the maximum pressure shifted along the extended line of the gas-liquid equilibrium in the supercritical region in the pressure-temperature phase plan. This finding seems to be related to the singular behavior of some properties of supercritical carbon dioxide along this line reported in the literature [167].

Myristic acid was esterified by ethanol using a hog pancreas lipase in supercritical carbon dioxide in $37 \%$ yield, while a similar enzyme-catalyzed reaction performed in acetonitrile yielded only $4 \%$ of the required product [168].

Immobilized lipases from Thermomyces (Humicola) lanuginosa and Candida antarctica (lipase B) were employed for modification (alcoholysis and glyceride synthesis) of cod liver oil with ethanol in supercritical carbon dioxide [169]; fish oil is rich in important PUFAs, like many plant and seed oils, and unlike animal fats. Long-chain FA esters with fatty alcohols are useful functional molecules in 
pharmaceutical, cosmetic and lubricant industry. Knez et al. [170, 171] used lipase from Rhizomucor miehei (Lipozyme RM IM) as catalyst for production of 1-octyl oleate in supercritical carbon dioxide, and studied the influence of parameter changes to the conversion rate in bench-scale packed-bed reactor. The authors got $93 \%$ maximum yield of the product at a substrate flow rate of $18 \mathrm{~mL} / \mathrm{h}$ and the $\mathrm{CO}_{2}$ flow rate of $210 \mathrm{~mL} / \mathrm{h}$, and the immobilized enzyme was able to act as catalyst up to 50 days. They proved a possibility of using such a system for continuous production process.

Modification of castor oil in supercritical carbon dioxide may be an example of C. antarctica immobilized lipase B catalyzing interesterification between castor oil TAGs and methyl oleate in $90 \%$ yield within 5 hours [172]. Even naturally occurring aliphatic amides, like capsaicin (8-methyl- $N$ vanillyl-6-nonenamide), a compound from the red pepper seeds, promoting blood circulation, are compounds of interest for pharmacology. It is relatively hardly available in broad scale. Palmitoyl vanillylamide, one of its analogs, can be synthesized through amidation by immobilized Mucor miehei lipase in supercritical carbon dioxide under optimized conditions $\left(50^{\circ} \mathrm{C}, 17 \mathrm{MPa}, \mathrm{pH} 8,8\right.$ hours $)$ from vanillylamide hydrochloride and palmitic anhydride at a molar ratio $5 / 15$, and enzyme concentration of $0.5 \%(\mathrm{w} / \mathrm{w})$ [173].

The course of the lipase-catalyzed reactions in supercritical carbon dioxide is always affected by the presence of moisture. Continuous acidolysis of triolein and stearic acid was studied [174] using the moist immobilized lipase in supercritical carbon dioxide in a large scale process at $50{ }^{\circ} \mathrm{C}, 16.9 \mathrm{MPa}$ and adsorbed water concentration of $2 \%(\mathrm{w} / \mathrm{w})$. The production rate was about $0.03 \mathrm{mmol} / \mathrm{h}$ per each $1 \mathrm{~g}$ of the immobilized enzyme.

The activity of several lipases was studied in subsequent enzymic transformation processes, after having used them as biocatalysts of blackcurrant (Ribes nigrum) oil hydrolysis in supercritical carbon dioxide. The subsequent reactions were performed at $40{ }^{\circ} \mathrm{C}$ and $15 \mathrm{MPa}$ in a continuous flow reactor. The most remarkable increase of enzyme activity was observed with a lipase from Rhizopus arrhizus and with Lipozyme (lipase from Mucor miehei immobilized on macroporous resin) [175].

\subsection{Separation and lipase-catalyzed modifications of phytosterols and related minor compounds}

Increasing importance of nutritional and pharmaceutical components (phytosterols, vitamins etc.) of plant oils has resulted in developing new sustainable processing methods [176]. Supercritical carbon dioxide extraction and fractionation techniques have been positively examined as alternative methods of obtaining plant and seed oils with high purity and quality [176, 177], and minor components of plant and seed oils (vitamins, phytosterols, isoprenes etc.) can also be separated. Canadian canola oil is one of the most known and most commercialized oils. Value-added processing of canola oil deodorizer distillate (concentrated mixture of phytosterols and tocopherols) has benefited the canola oil processing industry in Canada [178].

Synthesis of esters derived from phytosterols or other steroid alcohols and FAs is of great importance, due to their recent recognition and application in the food industry as cholesterol-lowering agents. Several enzymes were screened as catalysts, and optimal conditions were determined for the reaction between various FAs and sterols / phytosterols (e.g., cholesterol, sitostanol etc.) in supercritical carbon dioxide [156, 179]. Using an analytical supercritical fluid extraction unit, the lipase derived from Burkholderia cepacia, Chirazyme L-1, was appointed to be the most selective for 
facilitating the desired reactions [180]. $\mathrm{FAs}_{8}-\mathrm{C}_{18}$, a pressure range of $20.7-31 \mathrm{MPa}$, a temperature range of $40-60{ }^{\circ} \mathrm{C}$, along with variable flow rates, and initial static hold times were used to evaluate the feasibility of the above reaction. The yield of the cholesterol esters, as measured by supercritical fluid chromatography, ranged from $90 \%$ for caprylic acid to $99 \%$ for palmitic acid, while the corresponding reaction between sitostanol and the same FAs produced yields of $92 \%$ for caprylic acid and $99 \%$ for palmitic acid, respectively [156]. The extraction apparatus was modified to provide a continuous flow of the reagent FA and phytosterol or other steroid alcohols over the enzyme bed, thereby allowing continuous production of the desired esters, which averaged a $99 \%$ yield under optimal conditions [156].

\subsection{Lipase-catalyzed reactions in ionic liquid / supercritical carbon dioxide biphasic systems}

A synthesis of butyl esters (propanoate, laurate etc.) in a recirculating bioreactor using ionic liquid / supercritical carbon dioxide biphasic systems at $50{ }^{\circ} \mathrm{C}$ and $8 \mathrm{MPa}$ was described as an example of application of biphasic systems [181,182], in which $\alpha$-alumina microporous membranes with immobilized Candida antarctica lipase B were coated with four different ionic liquids based on 1-nalkyl-3-imidazolium cations and hexafluorophosphate and bis \{(trifluoromethyl)sulfonyl $\}$ imide anions. Selectivity increased up to $>99.5 \%$ when the ionic liquid / supercritical carbon dioxide biphasic system was used rather than supercritical carbon dioxide alone (at room temperature). The activity in room temperature ionic liquid / supercritical carbon dioxide biphasic systems depends on the effect of the ionic liquid media on the enzyme and the diffusion limitations across the ionic liquid layer around the biocatalyst.

\section{Conclusions: Importance of the reaction media for sustainability}

Extraction of compounds from natural sources has been the most widely studied application of supercritical fluids with several hundreds of published scientific papers (cf. review [39]). Supercritical fluid extraction has immediate advantages over traditional extraction techniques: it is a flexible process due to the possibility of continuous modulation of the solvent power / selectivity of the supercritical fluid, allows the elimination of polluting organic solvents and of the expensive post-processing of the extracts for solvent elimination. Supercritical carbon dioxide, a 'green' and sustainable medium, is nowadays the most frequently used supercritical fluid for productions in nutraceutic, cosmetic and pharmaceutical industry.

Supercritical fluid extractions, fractionations of the extracts, and their enzyme-catalyzed modifications have been developed and have expanded tremendously in many fields of products. This approach is also scientifically challenging but also necessary to find applications that are industrially competitive with the traditional processes based on cheaper technologies and plants. In some cases, the extraction problems proved to be very complex and as a consequence more evolved process schemes (multistep extractions, continuous solid processing, multistage separations, co-solvent or ionic liquid applications) have been adopted to overcome these problems. However, a large quantity of work is still required. Nevertheless, numbers of reviews have recently appeared which have shown perspectives of application of supercritical fluid technology in many areas of research and industrial production [39, 45-47, 108, 109, 183-185]. 


\section{Acknowledgments}

The authors thank to the research project of the Institute of Organic Chemistry and Biochemistry Z40550506 (MZ), and the Ministry of Education for the grant 2B06024 (SUPRAFYT), a part of the National Research Program II (ZW), for funding, and Mrs. M. Wimmerová for helpful discussion.

\section{References}

1. Emken, E.A.; Adlof, R.O.; Gulley, R.M. Dietary linoleic acid influences desaturation and acylation of deuterium-labeled linoleic and linolenic acids in young adult males. Biochim. Biophys. Acta 1994, 1213, 277-288.

2. Holub, D.J.; Holub, B.J. Omega-3 fatty acids from fish oils and cardiovascular disease. Mol. Cell Biochem. 2004, 263, 217-225.

3. Peet, M.; Brind, J.; Ramchand, C.N.; Shah, S.; Vankar, G.K. Two double blind placebo controlled pilot studies of eicosapentaenoic acid in the treatment of schizophrenia. Schizophr. Res. 2001, 49, 243-251.

4. Simopoulos, A.P. Omega-3 fatty acids in health and disease and in growth and development. Am. J. Clin. Nutr. 1991, 54, 438-463.

5. von Schacky, C. Omega-3 fatty acids and cardiovascular disease. Curr. Opin. Clin. Nutr. Metab. Care 2004, 7, 31-136.

6. Stahl, S.M. Essential psychopharmacology. Neuroscientific basis and practical applications, $2^{\text {nd }}$ Ed.; Cambridge University Press: Cambridge, 2000.

7. Glen, A.I.M.; Ross, B.M. Eicosanoids in the central nervous system. In The Eicosanoids; CurtisPrior, P., Ed.; Wiley: London, UK, 2004; pp. 210-220.

8. Carlezon, W.A., Jr.; Mague, S.D.; Parow, A.M.; Stoll, A.L.; Cohen, B.M.; Renshaw, P.F. Antidepressant-like effects of uridine and omega-3 fatty acids are potentiated by combined treatment in rats. Biol. Psychiatry 2005, 57, 343-350.

9. Ross, B.M.; Seguin, J.; Sieswerda, L.E. Omega-3 fatty acids as treatments for mental illness: Which disorder and which fatty acid? Lipids Health Dis. 2007, 6, 21-30.

10. Xiao, Y.F.; Sigg, D.C.; Leaf, A. The antiarrhythmic effect of n-3 polyunsaturated fatty acids: Modulation of cardiac ion channels as a potential mechanism. J. Membr. Biol. 2005, 206, 141-154.

11. Wigmore, S.J.; Ross, J.A.; Falconer, J.S.; Plester, C.E.; Tisdade, M.J.; Carter, D.C.; Faron, K.C.H. Effect of PUFA on the progress of cachexia in patiens with pancreatic cancer. Nutrition 1996, 12, 27-30.

12. Beaubaire, N.A.; Simon, J.E. Production potential of Borago oficinalis L. Acta Horticult. 1987, 208, 101-103.

13. Senanayake, S.P.J.N.; Shahidi, F. Enzyme-assisted acidolysis of borage (Borago officinalis L.) and evening primrose (Oenothera biennis L.) oils: Incorporation of omega-3 polyunsaturated fatty acids. J. Agric. Food Chem. 1999, 47, 3105-3112.

14. Stránský, K.; Zarevúcka, M.; Wimmer, Z. Gas chromatography analysis of blackcurrant oil in relation to its stability. Food Chem. 2005, 92, 569-573.

15. Traitler, H.; Wille, H.J.; Studer, A. Fractionation of Blackcurrant seed oil. J. Am. Oil Chem. Soc. 1988, 65, 755-760. 
16. Wille, H.J.; Traitler, H.; Lagarde, M. Preparation of stearidonic acid concentrates. Fat Sci. Technol. 1991, 93, 362-368.

17. Traitler, H.; Wille, H.J. Isolation of pure fatty acids from fats and oils. Fat Sci. Technol. 1992, 94, 506-511.

18. Syed Rahmatullah, M.S.K.; Shukla, V.K.S.; Mukherjee, K.D. Enrichment of $\gamma$-linolenic acid from evening primrose oil and borage oil via lipase-catalyzed hydrolysis. J. Am. Oil Chem. Soc. 1994, $71,560-573$.

19. Syed Rahmatullah, M.S.K.; Shukla, V.K.S.; Mukherjee, K.D. $\gamma$-Linolenic acid concentrates from borage and evening priprose oil via lipase-catalyzed esterification. J. Am. Oil Chem. Soc. 1994, $71,563-577$.

20. Kawashima, H.; Sakuradani, E.; Kamada, N.; Akimoto, K.; Konishi, K.; Ogawa, J.; Shimizu, S. Production of 8,11,14,17-cis-eicosatetraenoic acid (20:4 omega-3) by a Delta 5 and Delta 12 desaturase-defective mutant of an arachidonic acid-producing fungus Mortierella alpina 1S-4. J. Am. Oil Chem. Soc. 1998, 75, 1495-1500.

21. Shinmen, Y.; Shimizu, S.; Akimoto, D.; Kawashima, H.; Yamada, H. Production of arachidonic acid by Mortierella fungi. Selection of a potent producer and optimization of culture conditions for large-scale production. Appl. Microbiol. Biotechnol. 1989, 31, 11-16.

22. Yongmanitchai, W.; Ward, O.P. Screening of algae for potential alternative sources of eicosapentaenoic acid. Phytochemistry 1991, 30, 2963-2967.

23. Nichols, B.W.; Appleby, R.S. The distribution and biosynthesis of arachidonic acid in algae. Phytochemistry 1969, 8, 1907-1915.

24. Monroig, O.; Navarro, J.C.; Amat, F.; Gonzáles, P.; Bermejo, A.; Hontoria, F. Enrichment of Artemia nauplii in essential fatty acids with different types of liposomes and their use in the rearing of gilthead sea bream (Sparus aurata) larvae. Aquaculture 2006, 251, 491-508.

25. Zhu, J.-J.; Shi, J.-H.; Qian, W.-B.; Cai, Z.-Z.; Li, D. Effects of krill oil on serum lipids of hyperlipidemic rats and human SW480 cells. Lipids Health Dis. 2008, 7, 30; DOI: 10.1186/1476511X-7-30.

26. Shimada, Y.; Sugihara, A.; Nakano, H.; Kuramoto, T.; Nagao, T.; Gemba, M.; Tominaga, Y. Purification of docosahexaenoic acid by selective esterification of fatty acids from tuna oil with Rhizopus delemar lipase. J. Am. Oil Chem. Soc. 1997, 74, 97-101.

27. Salunkhe, D.K.; Chavan, J.K.; Adsule, R.N.; Kadam, S.S. World Oilseeds: Chemistry, Technology, and Utilization. Salunkhe, D.K., Van Nostrand, R., Eds.; Springer: New York, USA; 1992.

28. Gunstone, F.D.; Ilyas-Qureshi, M. Glyceride studies. Part IV. The component glycerides of ten seed oils containing linoleic acid. J. Am. Oil. Chem. Soc. 1965, 42, 961-965.

29. Gunstone, F.D.; Hamilton, R. J.; Padley, F.B.; Ilyas-Qureshi, M. Glyceride studies. V. The distribution of unsaturated acyl groups in vegetable triglycerides. J. Am. Oil. Chem. Soc. 1965, 42, 965-970.

30. Biermann, U.; Friedt, W.; Lang, S.; Lühs, W.; Machmüller, G.; Metzger, J.O.; Rüsch gen. Klaas, M.; Schäfer, J.; Schneider, M.P. New syntheses with oils and fats as renewable raw materials for the chemical industry. Angew. Chem. Int. Ed. Engl. 2000, 39, 2206-2224. 
31. Hayes, D.G. Enzyme-catalyzed modification of oilseed materials to produce eco-friendly products. J. Am. Oil Chem. Soc. 2004, 81, 1077-1103.

32. Gandhi, N.N. Applications of lipase. J. Am. Oil Chem. Soc. 1997, 74, 621-634.

33. Albasi, C.; Bertrand, N.; Riba, J.P. Enzymatic hydrolysis of sunflower oil in a standardized agitated tank reactor. Bioprocess Eng. 1999, 20, 77-81.

34. Martinez, O.; Wilhelm, A.M.; Riba, J.P. Kinetic-study of an enzymatic liquid liquid reaction - the hydrolysis of tributyrin by Candida cylindracea lipase. J. Chem. Tech. Biotechnol. 1992, 53, 373378.

35. Habulin, M.; Knez, Ž. High-pressure enzymatic hydrolysis of oil. Eur. J. Lipid Sci. Technol. 2002, 104, 381-386.

36. Malcata, F.X.; Reyes, H.R.; Garcia, H.S.; Hill, C.G., Jr.; Amundson, C.H. Immobilized lipase reactions for modification of fats and oils - A review. J. Am. Oil Chem. Soc. 1990, 67, 890-910.

37. Bogel-Lukasik, R. Sustainable processes employing ionic liquids for secondary alcohols separation. Monatsh. Chem. 2007, 138, 1137-1144.

38. Dordick, J.S. Nonaqueous enzymology. Curr. Opin. Biotechnol. 1991, 2, 401-407.

39. Reverchon, E.; De Marco, I. Supercritical fluid extraction and fractionation of natural matters. $J$. Supercrit. Fluids 2006, 38, 146-166.

40. Klibanov, A.M. Improving enzymes by using them in organic solvents. Nature 2001, 409, 241-246.

41. Schoffers, E.; Golebioeski, A.; Johnson, C.R. Enantioselective synthesis through enzymatic asymmetrization. Tetrahedron 1996, 52, 3769-3826.

42. Klibanov, A.M. Why are enzymes less active in organic solvents than in water? Trends Biotechnol. 1997, 15, 97-101.

43. Schmid, R.D.; Verger, R. Lipases: Interfacial enzymes with attractive applications. Angew. Chem. Int. Ed. Engl. 1998, 37, 1608-1633.

44. Beisson, F.; Tiss, A.; Riviere, C.; Verger, R. Methods for lipase detection and assay: A critical review. Eur. J. Lipid Sci. Technol. 2000, 133-153.

45. Krishna, H.S.; Karanth, N.G. Lipases and lipase-catalyzed esterification reactions in nonaqueous media. Catal. Rev. 2002, 44, 499-591.

46. Patel, R.N. Microbial/enzymatic synthesis of chiral intermediates for pharmaceuticals. Enzyme Microb. Technol. 2002, 31, 804-826.

47. Patel, R.N. Biocatalytic synthesis of chiral pharmaceutical intermediates. Food Technol. Biotechnol. 2004, 42, 305-325.

48. Wong, C.-H.; Whitesides, G.M. Enzymes in Synthetic Organic Chemistry. Pergamon: Oxford, UK, 1994.

49. Dias, S.F.; Vilas-Boas, L.; Cabral, J.M.S.; Fonseca, M.M.R. Production of ethyl butyrate by Candida rugosa lipase immobilized in polyurethane. Biocatalysis 1991, 5, 21-34.

50. Macrae, A.R. Biocatalysts in Organic Synthesis. Tramper, J., van der Plas, H.C., Linko, P., Eds.; Elsevier: Amsterdam, The Netherlands, 1985.

51. Muderhwa, J.M.; Pina, M.; Graille, J. Interesterification catalyzed by 1-3 regioselective lipases without solvent-valorization of palm oil and its solid fraction. Rev. Fr. Corps Gras 1989, 36, 11-19. 
52. Kyotani, S.; Nakashima, T.; Izumoto, E.; Fukuda, H. Continuous interesterification of oils and fats using dried fungus immobilized in biomass support particles. J. Ferment. Bioeng. 1991, 71, 286-288.

53. Mojovič, L.; Siler-Marinkovič, S.; Kukič, G.; Vunjak-Novakovič, G. Rhizopus arrhizus lipasecatalyzed interesterification of the midfraction of palm oil to a cocoa butter equivalent fat. Enzyme Microb. Technol. 1993, 15, 438-443.

54. Forssell, P.; Paruvuori, P.; Linko, P.; Poutanen, K. Enzymatic transesterification of rapeseed oil and lauric acid in a continuous reactor. J. Am. Oil Chem. Soc. 1993, 70, 1105-1109.

55. Ghazali, H.M.; Hamidah, S.; Che Man, Y.B. Enzymatic transesterification of palm olein with nonspecific and 1,3-specific lipases. J. Am. Oil Chem. Soc. 1995, 72, 633-639.

56. Soumanou, M.M.; Bornscheuer, U.T.; Menge, U.; Schmid, R.D. Synthesis of structured triglycerides from peanut oil with immobilized lipase. J. Am. Oil Chem. Soc. 1997, 74, 427-433.

57. Ghosh, S.; Bhattacharyya, D.K. Utilization of high-melting palm stearin in lipase-catalyzed interesterification with liquid oils. J. Am. Oil Chem. Soc. 1997, 74, 589-592.

58. Mukesh, D.; Banerji, A.A.; Newadkar, R.; Bevinakatti, H.S. Lipase catalysed transesterification of vegetable oils - A comparative study in batch and tubular reactors. Biotechnol. Lett. 1993, 15, 77-82.

59. Xu, X.; Balchen, S.; Høy, C.-E.; Adler-Nissen, J. Pilot batch production of specific-structured lipids by lipase-catalyzed interesterification: Preliminary study on incorporation and acyl migration. J. Am. Oil Chem. Soc. 1998, 75, 301-308.

60. Seriburi, V.; Akoh, C.C. Enzymatic transesterification of triolein and stearic acid and solid fat content of their products. J. Am. Oil Chem. Soc. 1998, 75, 511-516.

61. Mu, H.; Xu, X.; Høy, C.-E. Production of specific-structured triacylglycerols by lipase-catalyzed interesterification in a laboratory-scale continuous reactor. J. Am. Oil Chem. Soc. 1998, 75, 1187 1193.

62. Ferreira-Dias, S.; Duarte, C.S.; Falaschi, V.; Marques, S.R.; Gusmao, J.H.; da Fonseca, M.M.R. Stability and Stabilization of Biocatalysts; Ballesteros, A., Plou, F.J., Iborra, J.L., Halling, P., Eds.; Elsevier: Amsterdam, The Netherlands, 1998.

63. Fomuso, L.B.; Akoh, C.C. Enzymatic modification of triolein: Incorporation of caproic and butyric acids to produce reduced-calorie structured lipids. J. Am. Oil Chem. Soc. 1997, 74, 269-272.

64. Xu, X.; Skands, A.R.H.; Høy, C.-E.; Mu, H.; Balchen, S.; Adler-Nissen, J. Production of specificstructured lipids by enzymatic interesterification: Elucidation of acyl migration by response surface design. J. Am. Oil Chem. Soc. 1998, 75, 1179-1186.

65. Miura, S.; Ogawa, A.; Konishi, H. A rapid method for enzymatic synthesis and purification of the structured triacylglycerol, 1,3-dilauroyl-2-oleoyl-glycerol. J. Am. Oil Chem. Soc. 1999, 76, 927931.

66. Adachi, S.; Okumura, K.; Ota, Y.; Mankura, M. Acidolysis of sardine oil by lipase to concentrate eicosapentaenoic and docosahexanoic acids in glycerides. J. Ferment. Bioeng. 1993, 75, 259-264.

67. Yamane, T.; Suzuki, T.; Hoshino, T. Increasing n-3 polyunsaturated fatty acid content of fish oil by temperature control of lipase-catalyzed acidolysis. J. Am. Oil Chem. Soc. 1993, 70, 1285-1287.

68. Li, Z.; Ward, O.P. Enzyme catalysed production of vegetable oils containing omega-3 polyunsaturated fatty acid. Biotechnol. Lett. 1993, 15, 185-188. 
69. Huang, K.-H.; Akoh, C.C. Lipase-catalyzed incorporation of n-3 polyunsaturated fatty acids into vegetable oils. J. Am. Oil Chem. Soc. 1994, 71, 1277-1288.

70. Lee, K.-T.; Akoh, C.C. Immobilized lipase-catalyzed production of structured lipids with eicosapentaenoic acid at specific positions. J. Am. Oil Chem. Soc. 1996, 73, 611-615.

71. Senanayake, S.P.J.N.; Shahidi, F. Enzymatic incorporation of docosahexaenoic acid into borage oil. J. Am. Oil Chem. Soc. 1999, 76, 1009-1015.

72. Jennings, B.H.; Akoh, C. Enzymatic modification of triacylglycerols of high eicosapentaenoic and docosahexaenoic acids content to produce structured lipids. J. Am. Oil Chem. Soc. 1999, 76, 1133-1137.

73. Haraldsson, G.; Thorarensen, A. Preparation of phospholipids highly enriched with n-3 polyunsaturated fatty acids by lipase. J. Am. Oil Chem. Soc. 1999, 76, 1143-1149.

74. Muderhwa, J.M.; Pina, M.; Montet, D.; Feuillard, P.; Graille, J. 1-3 Regioselective enzymatic interesterification in a melted medium and a continuous reactor - valorization of palm oil. Oleagineux 1989, 44, 36-43.

75. Zainal, Z.; Yusoff, M.S.A. Enzymatic interesterification of palm stearin and palm kernel olein. $J$. Am. Oil Chem. Soc. 1999, 76, 1003-1008.

76. Bergstrom, B.; Brochmann, H.L. Lipases, $1^{\text {st }}$ Ed.; Elsevier: Amsterdam, The Netherlands, 1984.

77. Quinlan, P.; Moore, S. Modification of triglycerides by lipases: Process technology and its application to the production of nutritionally improved fats. INFORM 1993, 4, 580-585.

78. Brady, L.; Brzozowski, A.M.; Derewenda, Z.S.; Dodson, E.; Dodson, G.; Tolley, S.; Turkenburg, J. P.; Christiansen, L.; Huge-Jensen, B.; Norskov, L.; Thim, L.; Menge, U. A serine protease triad forms the catalytic centre of a triacylglycerol lipase. Nature 1990, 343, 767-770.

79. Klibanov, A.M. Why are enzymes less active in organic solvents than in water? Trends Biotechnol. 1997, 15, 97-101.

80. Pleiss, J.; Fischer, M.; Peiker, M.; Thiele, C.; Schmid, R.D. Lipase engineering database. Understanding and exploiting sequence-structure-function relationships. J. Mol. Catal. B: Enzym. 2000, 10, 491-508.

81. Balcao, V.M.; Paiva, A.L.; Malcata, F.X. Review. Bioreactors with immobilized lipases: State of the art. Enzyme Microb. Technol. 1996, 18, 392-416.

82. Deng, H.T.; Xu, Z.K.; Huang, X.J.; Wu, J.; Seta, P. Adsorption and activity of Candida rugosa lipase on polypropylene hollow fiber membrane modified with phospholipid analogous polymers. Langmuir 2004, 20, 10168-10173.

83. Homquist, M.; Norin, M.; Hult, K. The role of arginines in stabilizing the active open-lid conformation of Rhizomucor meihei lipase. Lipids 1993, 28, 721-726.

84. Villeneuve, P.; Muderwha, J.; Graille, J.; Haas, M. Customizing lipases for biocatalysis: A survey of chemical, physical and molecular biological approaches. J. Mol. Catal. B: Enzym. 2000, 9, 113-148.

85. Holmquist, M.; Martinelle, M.; Berglund, P.; Clausen, I.G.; Patkar, S.; Svendsen, A.; Hult, K. Lipases from Rhizomucor miehei and Thermomyces lanuginosa: modification of the lid covering the active site alters enantioselectivity. J. Protein Chem. 1993, 12, 749-757. 
86. Gutierrez-Ayesta, C.; Carelli, A.A.; Ferreira, M.L. Relation between lipase structures and their catalytic ability to hydrolyse triglycerides and phospholipids. Enzyme Microb. Technol. 2007, 41, $35-43$.

87. Pleiss, J.; Fisher, M.; Schmid, R.D. Anatomy of lipase binding sites: the scissile fatty acid binding site. Chem. Phys. Lipids 1998, 93, 67-80.

88. Bottino, N.R.; Vandenburg, G.A.; Reiser, R. Resistance of certain long chain polyunsaturated fatty acids of marine oils to pancreatic lipase hydrolysis. Lipids 1967, 2, 489-493.

89. Jensen, R.G.; Gordon, D.T. Specificity of Geotrichum candidum lipase with respect to double bond position in triglycerides containing cis-octadecenoic acids. Lipids 1972, 7, 738-741.

90. Lopez-Martinez, J.C.; Campra-Madrid, P.; Ramirez-Fajardo, A.; Esteban-Cerdan, L.; GuilGuerrero, J.L. Screening of lipases for enzymatic concentration of gamma-linolenic acid (GLA) from seed oils. J. Food Lipids 2006, 13, 362-374.

91. Hoshino, T.; Yamane, T.; Shimizu, S. Selective hydrolysis of fish oil by lipase to concentrate n-3 polyunsaturated fatty acid. Agric. Biol. Chem. 1990, 54, 1459-1467.

92. Tanaka, Y.; Hirano, J.; Funada, T. Concentration of docosahexaenoic acid glyceride by hydrolysis of fish oil with Candida cylindracea lipase. J. Am. Oil Chem. Soc. 1992, 69, 1210-1214.

93. Basheer, S.; Plat, D. Enzymatic modification of sterols using sterol-specific lipase. WO patent 2001-075083; 2001.

94. Weber, N.; Weikamp, P.; Mukherjee, K.D. Cholesterol-lowering food additives: Lipase-catalyzed preparation of phytosterol and phytostanol esters. Food Res. Intl. 2002, 35, 177-181.

95. Bertinotti, A.; Carrea, G.; Ottolina, G.; Riva, S. Regioselective esterification of polyhydroxylated steroids by Candida antarctica lipase B. Tetrahedron 1994, 50, 13165-13172.

96. Norinobu, S.; Senoo, N.; Kaneko, S.; Sato, F; Mankura, M. Supercritical preparation of sterol fatty esters with enzyme. Japanese patent 2002-233396; 2002.

97. Stamatis, H.; Sereti, V.; Kolisis, F.N. Studies on the enzymatic synthesis of lipophilic derivatives of natural antioxidants. J. Am. Oil Chem. Soc. 1999, 76, 1505-1510.

98. Jessop, P.G.; Ikariya, T.; Noyori, R. Homogenous catalysis in supercritical fluids. Chem. Rev. 1999, 99, 475-494.

99. Brennecke, J.F.; Chateauneuf, J.E. Homogenous organic reactions as mechanistic probes in supercritical fluids. Chem. Rev. 1999, 99, 433-452.

100. Baiker, A. Supercritical fluids in heterogenous catalysis. Chem. Rev. 1999, 99, 453-474.

101. Darr, J.A.; Poliakoff, M. New directions in inorganic and metal-organic coordination chemistry in supercritical fluids. Chem. Rev. 1999, 99, 495-542.

102. Kiran, E.; Debenedetti, P.G.; Peters, C.J. Supercritical Fluids Fundamentals and Applications; Kluwer Academic: Dordrecht, The Netherlands, 2000.

103. Leitner, W. Supercritical carbon dioxide as a green reaction medium for catalysis. Acc. Chem. Res. 2002, 35, 746-756.

104. Matsuda, T.; Watanabe, K.; Harada, T.; Nakamura, K. Enzymatic reactions in supercritical CO2: carboxylation, asymmetric reduction and esterification. Catal. Today 2004, 96, 103-111.

105. Kragl, U.; Eckstein, M.; Kraftzik, N. Biocatalytic reactions in ionic liquids. In Ionic Liquids in Synthesis; Wasserscheid, P., Welton, T., Eds.; Wiley-VCH: Weinheim, Germany, 2003; pp. 336-347. 
106. Seddon, K.R. Ionic liquids for clean technology. J. Chem. Technol. Biotechnol. 1997, 68, 351-356.

107. Welton, T. Room-temperature ionic liquids. Solvents for synthesis and catalysis. Chem. Rev. 1999, 99, 2071-2084.

108. Yang, Z.; Pan, W. Ionic liquids: Green solvents for nonaqueous biocatalysis. Enzyme Microb. Technol. 2005, 37, 19-28.

109. Chowdhury, S.; Mohan, R.S.; Scott, J.L. Reactivity in ionic liquids. Tetrahedron 2007, 63, 2363-2389.

110. Freemantle, M. Ionic liquids in organic synthesis. Chem. Eng. News 2004, 82, 44-49.

111. Roberts, N.J.; Seago, A.; Carey, J.S.; Freer, R.; Preston, C.; Lye, G.J. Lipase catalysed resolution of the Lotrafiban intermediate 2,3,4,5-tetrahydro-4-methyl-3-oxo-1H-1,4-benzodiazepine-2-acetic acid methyl ester in ionic liquids: Comparison to the industrial t-butanol process. Green Chem. 2004, 6, 475-482.

112. Lau, R.M.; Sorgedrager, M.J.; Carrea, G.; van Rantwijk, F.; Secundo, F.; Sheldon, R.A. Dissolution of Candida antarctica lipase B in ionic liquids: effects on structure and activity. Green Chem. 2004, 6, 483-487.

113. Oliveira, J.V.; Oliveira, D. Kinetics of the enzymatic alcoholysis of palm kernel oil in supercritical $\mathrm{CO}_{2}$. Ind. Eng. Chem. Res. 2000, 39, 4450-4454.

114. Kamat, S.V.; Beckman, E.J.; Russell, A.J. Enzyme-activity in supercritical fluids. Crit. Rev. Biotechnol. 1995, 15, 41-71.

115. Connstein, W.; Hoyer, E.; Wartenberg, H. The enzymic decomposition of fat. Chem. Ber. 1902, 34, 3988-4006.

116. Baumann, H.; Bühler, M.; Fochem, H.; Hirsinger, F.; Zoebelein, H.; Falbe, J. Natural fats and oils - renewable raw materials for the chemical industry. Angew. Chem. Int. Ed. Engl. 1988, 27, 41-62.

117. Moquin, P.H.L.; Temelli, F. Production of monoolein from oleic acid and glycerol in supercritical carbon dioxide media: a kinetic approach. J. Supercrit. Fluids 2008, 44, 40-47.

118. Promožič, M.; Habulin, M.; Knez, Ž. Parameter optimization for enzymic hydrolysis of sunflower oil in high-pressure reactors. J. Am. Oil Chem. Soc. 2003, 80, 643-646.

119. Promožič, M.; Habulin, M.; Knez, Ž. Thermodynamic properties of the enzymatic hydrolysis of sunflower oil in high-pressure reactors. J. Am. Oil Chem. Soc. 2003, 80, 785-788.

120. Promožič, M.; Habulin, M.; Knez, Ž. Modeling of kinetics for the enzymatic hydrolysis of sunflower oil in a high-pressure reactors. J. Am. Oil Chem. Soc. 2005, 82, 543-547.

121. Zarevúcka, M.; Vacek, M.; Wimmer, Z.; Stránský, K.; Koutek, B.; Demnerová, K. Enzymic transformations of blackcurrant oil: enrichment with $\gamma$-linolenic acid and $\alpha$-linolenic acid. Chem. Listy 2003, 97, 206-213.

122. Sovová, H.; Zarevúcka, M. Lipase-catalysed hydrolysis of blackcurrant oil in supercritical carbon dioxide. Chem. Eng. Sci. 2003, 58, 2339-2350.

123. Bártlová, M.; Bernášek, P.; Sýkora, J.; Sovová, H. HPLC in reversed phase mode: Tool for investigation of kinetics of blackcurrant seed oil lipolysis in supercritical carbon dioxide. $J$. Chromatogr. B 2006, 839, 80-84.

124. Sýkora, J.; Bernášek, P.; Zarevúcka, M.; Kurfürst, M.; Sovová, H.; Schraml, J. High-performance liquid chromatography with nuclear magnetic resonance detection - A method for quantification 
of $\alpha$ - and $\gamma$-linolenic acids in their mixtures with free fatty acids. J. Chromatogr. A 2007, 1139, 152-155.

125. Kosugi, Y.; Azuma, N.; Synthesis of triacylglycerol from polyunsaturated fatty acid by immobilized lipase. J. Am. Oil Chem. Soc. 1994, 71, 1397-1403.

126. Cerdán, L.E.; Medina, A.R.; Giménez Giménez, A.; Ibánez González, M.J.; Molina Grima, E. Synthesis of PUFA enriched triglycerides by lipase catalyzed esterification. J. Am. Oil Chem. Soc. 1998, 75, 1329-1337.

127. Medina, A.R.; Cerdán, L.E.; Giménez Giménez, A.; Camacho Páez, B.; Ibánez González, M.J.; Molina Grima, E. Lipase-catalyzed esterification of glycerol and polyunsaturated fatty acids from fish and microalgae oils. J. Biotechnol. 1999, 70, 379-391.

128. Akoh, C.C.; Moussata, C.O. Lipase-catalyzed modification of borage oil: Incorporation of capric and eicosapentaenoic acids to form structured lipids. J. Am. Oil Chem. Soc. 1998, 75, 697-701.

129. McKenna, M.C.; Hubbard, V.S.; Aeri, J.G. Linoleic acid absorption for lipid supplements in patients with cystic fibrosis with pancreatic insufficiency and in control subjects. J. Pediatr. Gastroenterol. Nutr. 1985, 4, 45-48.

130. Kawashima, A.; Shimada, Y.; Nagao, T.; Ohara, A.; Matsuhisa, T.; Sugihara, A.; Tominaga, Y. Production of structured TAG rich in 1,3- dicapryloyl-2-c-linolenoyl glycerol from borage oil. $J$. Am. Oil Chem. Soc. 2002, 79, 871-877.

131. Kawashima, A.; Shimada, Y.; Yamamoto, M.; Sugihara, A.; Nagao, T.; Komemushi, S.; Tominaga, Y. Enzymatic synthesis of high-purity structured lipids with caprylic acid at 1,3positions and polyunsaturated fatty acid at 2-position. J. Am. Oil Chem. Soc. 2001, 78, 611-616.

132. Senanayake, S.P.J.N.; Shahidi, F. Chemical and stability of structured lipids from borage (Borago officinalis L.) and evening primrose (Oenothera biennis L.) oils. J. Food Sci. 2002, 67, 20382045.

133. Shimada, Y.; Suenaga, M.; Sugihara, A.; Seiichi, S.; Tominaga, Y. Continuous production of structured lipids containing clinolenic and caprylic acids by immobilized Rhizopus delemar lipase. J. Am. Oil Chem. Soc. 1996, 76, 189-193.

134. Hamam, F.; Shahidi, F. Synthesis of structured lipids via acidolysis of docosahexaenoic acid single cell oil (DHASCO) with capric acid. J. Agric. Food Chem. 2004, 52, 2900-2906.

135. Hamam, F.; Shahidi, F. Enzymatic acidolysis of arachidonic acid single cell oil (ARASCO) with capric acid. J. Am. Oil Chem. Soc. 2004, 81, 887-892.

136. Hamam, F.; Shahidi, F. Enzymatic incorporation of capric acid into a single cell oil rich in docosahexaenoic acid (DHA) and docosapentaenoic acid (DPA). Food Chem. 2005, 91, 583-591.

137. Iwasaki, Y.; Han, J.J.; Narita, M.; Rosu, R.; Yamane, T. Enzymatic synthesis of structured lipids from single cell oil of high docosahexaenoic acid content. J. Am. Oil Chem. Soc. 1999, 76, 563-569.

138. Yang, T.; Xu, X.; Li, L. Comparison of linoleic and conjugated linoleic acids in enzymatic acidolysis of tristearin. J. Food Lipids 2001, 8, 149-161.

139. Ronne, T.H.; Pederson, L.S.; Xu, X. Triglyceride selectivity of immobilized Thermomyces lanuginose lipase in interesterification. J. Am. Oil Chem. Soc. 2005, 82, 737-743.

140. Tsuzuki, W. Acidolysis between triolein and short-chain fatty acids by lipase in organic solvents. Biosci. Biotechnol. Biochem. 2005, 69, 1256-1261. 
141. Paez, B.C.; Medina, A.R.; Rubio, F.C.; Cerdan, L.E.; Grima, E.M. Kinetics of lipase-catalyzed interesterification of triolein and caprylic acid to produce structured lipids. J. Chem. Technol. Biotechnol. 2003, 78, 461-470.

142. Sellappan, S.; Akoh, C.C. Synthesis of structured lipids by transesterification of trilinolein catalyzed by Lipozyme IM60. J. Agric. Food Chem. 2001, 49, 1-9.

143. Fomus, L.B.; Akoh, C.C. Structured lipids: Lipase-catalyzed interesterification of tricaproin and trilinolein. J. Am. Oil Chem. Soc. 1998, 75, 405-410.

144. Hamam, F.; Shahidi F. Incorporation of selected long-chain fatty acids into trilinolein and trilinolenin. Food Chem. 2008, 106, 33-39.

145. Hamam, F.; Shahidi, F. Enzymatic incorporation of selected long-chain fatty acids into triolein. $J$. Am. Oil Chem. Soc. 2007, 84, 533-541.

146. Hamam, F.; Shahidi, F. Acidolysis of tristearin with selected long chain fatty acids. J. Agric. Food Chem. 2007, 55, 1955-1960.

147. Lee, K.; Akoh C. Characterization of enzymatically synthesized structured lipids containing eicosapentaenoic, docosahexaenoic, and caprylic acids. J. Am. Oil Chem. Soc. 1998, 75, 495-499.

148. McNeill, G.P.; Ackman, R.G.; Moore S.R. Lipase-catalyzed enrichment of long chain polyunsaturated fatty acids. J. Am. Oil Chem. Soc. 1996, 73, 1403-1414.

149. Schmid, U.; Bornscheuer, U.T.; Soumanou, M.M.; Mc- Neill, G.P.; Schmid, R.D. Optimization of the reaction conditions in the lipase-catalyzed synthesis of structured triglycerides. J. Am. Oil Chem. Soc. 1998, 75, 1527-1531.

150. Soumanou, M.M.; Bornscheuer, U.T.; Schmid R.D. Two step enzymatic reaction for synthesis of pure structured triacylglycerides. J. Am. Oil Chem. Soc. 1998, 75, 703-710.

151. Tsujisaka, Y.; Okumura, S.; Iwai, M. Glyceride synthesis by four kinds of microbial lipase. Biochim. Biophys. Acta 1977, 489, 415-422.

152. Okumura, S.; Iwai, M.; Tsujisaka, Y. Synthesis of various kinds of esters by four microbial lipases. Biochim. Biophys. Acta 1979, 575, 156-165.

153. Liu, K.-J.; Chang, H.-M.; Liu, K.-M. Enzymatic synthesis of cocoa butter analog through interesterification of lard and tristearin in supercritical carbon dioxide by lipase. Food Chem. 2007, 100, 1303-1311.

154. Sakurai, H.; Pokorný, J. The development and application of novel vegetable oils tailor-made for specific human dietary needs. Eur. J. Lipid Sci. Technol. 2003, 105, 769-778.

155. Jessop, P.; Leitner, W. Chemical synthesis using supercritical fluids. Wiley-VCH: Weinheim, 1999.

156. King, J.W.; Snyder, J.M.; Frykman, H.; Neese, A. Sterol ester production using lipase-catalyzed reactions in supercritical carbon dioxide. Eur. Food Res. Technol. 2001, 212, 566-569.

157. Gunnlaugsdottir, H.; Järemo, M.; Sivik, B. Process parameters influencing ethanolysis of cod liver oil in supercritical carbon dioxide. J. Supercrit. Fluids 1998, 12, 85-93.

158. Overmeyer, A.; Schrader-Lippelt, S.; Kasche, V.; Brunner, G. Lipase-catalysed kinetic resolution of racemates at temperatures from $40{ }^{\circ} \mathrm{C}$ to $160{ }^{\circ} \mathrm{C}$ in supercritical $\mathrm{CO}_{2}$. Biotechnol. Lett. 1999, 21, 65-69.

159. Habulin, M.; Krmelj, V.; Knez, Ž. Synthesis of oleic acid esters catalyzed by immobilized lipase. J. Agric. Food Chem. 1996, 44, 338-342. 
160. Knez, Ž.; Habulin, M. Compressed gases as alternative enzymatic-reaction solvents: A short review. J. Supercrit. Fluids 2002, 23, 29-42.

161. Leitner, W. Die "bessere Lösung”? Chemische Synthese in überkritischem Kohlendioxid. Chem. Unserer Zeit 2003, 37, 32-38.

162. King, J.; Jackson, M.; Temelli, F. Development of industrially-useful synthetic processes in supercritical carbon dioxide. In I Fluidi Supercritici e le Lorno Applicazioni; Kikic, I., Alessi, P., Eds.; Trieste, Italy, 1995; pp. 19-26.

163. Bornscheuer, U.; Kazlauskas, R. Hydrolases in Organic Synthesis: Regio- and Stereoselective Biotransformations; Wiley-VCH: Weinheim, Germany, 1999.

164. Snyder, J.; King, J.; Jackson, M. Fat content for nutritional labeling by supercritical fluid extraction and an on-line lipase catalyzed reaction. J. Chromatogr. A 1996, 750, 201-207.

165. Anderson, M.; King, J.; Blomberg, L. Synthesis of fatty alcohol mixtures from oleochemicals in supercritical fluids. Green Chem. 2000, 2, 230-234.

166. Nakaya, H.; Nakamura, K.; Miyawaki, O. Lipase-catalyzed esterification of stearic acid with ethanol, and hydrolysis of ethyl stearate, near the critical point in supercritical carbon dioxide. $J$. Am. Oil Chem. Soc. 2002, 79, 23-27.

167. Ikushima, Y.; Saito, N.; Arai, M.; Blanch, H.W. Activation of lipase triggered by interactions with supercritical carbon dioxide in the near-critical region. J. Phys. Chem. 1995, 99, 8941-8944.

168. Srivastava, S.; Madras, G.; Modak, J. Esterification of myristic acid in supercritical carbon dioxide. J. Supercrit. Fluids 2003, 27, 55-64.

169. Gunnlaugsdottir, H.; Wannerberger, K.; Sivik, B. Alcoholysis and glyceride synthesis with immobilized lipase on controlled-pore glass of varying hydrophobicity in supercritical carbon dioxide. Enzyme Microb. Technol. 1998, 22, 360-367.

170. Laudani, C.G.; Habulin, M.; Primožič, M.; Knez, Ž.; Della Porta, G.; Reverchon, E. Optimisation of n-octyl oleate enzymatic synthesis over Rhizomucor miehei lipase. Bioprocess Biosyst. Eng. 2006, 29, 119-127.

171. Laudani, C.G.; Habulin, M.; Knez, Ž.; Della Porta, G.; Reverchon, E. Immobilized lipasemediated long-chain fatty acid esterification in dense carbon dioxide: bench-scale packed-bed reactor study. J. Supercrit. Fluids 2007, 41, 74-81.

172. Pomier, E.; Galy, J.; Paolucci-Jeanjean, D.; Pina, M.; Sarrade, S.; Rios, G.M. A new reactor

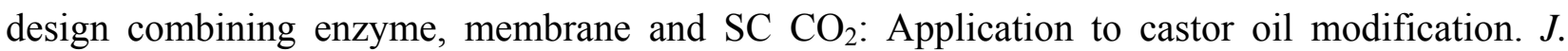
Membrane Sci. 2005, 249, 127-132.

173. Liu, K.-J.; Liu, K.-M.; Chang, H.-M. Biocatalytic synthesis of palmitoyl vanillylamide in supercritical carbon dioxide through amidation of vanillylamide hydrochloride and palmitic anhydride by lipase. Food Chem. 2007, 102, 1020-1026.

174. Hakoda, M.; Shiragami, N.; Enomoto, A.; Nakamura, K. Effect of moisture on enzymatic reaction in supercritical carbon dioxide. Bioprocess Biosyst. Eng. 2002, 24, 355-361.

175. Hlavsová, K.; Wimmer, Z.; Xanthakis, E.; Bernášek, P.; Sovová, H.; Zarevúcka, M. Lipase activity enhancement by SC-CO $\mathrm{CO}_{2}$ treatment. Z. Naturforsch. 2008, 63B, 779-784.

176. Eisenmenger, M.; Dunford, N.T.; Eller, F.; Tailor, S.; Martinez, J. Pilot-scale supercritical carbon dioxide extraction and fractionation of wheat germ oil. J. Am. Oil Chem. Soc. 2006, 83, 863-868. 
177. Lau, H.L.N.; Choo, Y.M.; Ma, A.N.; Chuah, C.H. Quality of residual oil from palm-pressed mesocarp fiber (Elaeis guineensis) using supercritical $\mathrm{CO}_{2}$ with and without ethanol. J. Am. Oil Chem. Soc. 2006, 83, 893-898.

178. Üstündag, Ö.G.; Temelli, F. Column fractionation of canola oil deodorizer distillate using supercritical carbon dioxide. J. Am. Oil Chem. Soc. 2007, 84, 953-961.

179. Nagesha, G.K.; Manohar, B.; Sankar, K.U. Enzymatic esterification of free fatty acids of hydrolyzed soy deodorizer distillate in supercritical carbon dioxide. J. Supercrit. Fluids 2004, 32, 137-145.

180. Frykman, H.B.; Snyder, J.M.; King, J.W. Screening catalytic lipase activities with an analytical supercritical fluid extractor. J. Am. Oil Chem. Soc. 1998, 75, 517-520.

181. Hernández, F.J..; de los Ríos, A.P.; Gómez, D.; Rubio, M.; Víllora, G. A new recirculating enzymatic membrane reactor for ester synthesis in ionic liquid/supercritical carbon dioxide biphasic systems. Appl. Catal. B: Environ. 2006, 67, 121-126.

182. Gumí, T.; Paolucci-Jeanjean, M.; Belleville, M.-P.; Rios, G.M. Enzymatic membrane reactor involving a hybrid membrane in supercritical carbon dioxide. J. Membrane Sci. 2007, 297, 98-103.

183. Wang, L.; Weller, C.L. Recent advances in extraction of nutraceuticals from plants. Trends Food Sci. Technol. 2006, 17, 300-312.

184. Ghanem, A. Trends in lipase-catalyzed asymmetric access to enantiomerically pure/enriched compounds. Tetrahedron 2007, 63, 1721-1754.

185. Jurček, O.; Wimmerová, M.; Wimmer, Z. Selected chiral alcohols: Enzymic resolution and reduction of convenient substrates. Coord. Chem. Rev. 2008, 252, 767-781.

(C) 2008 by the authors; licensee Molecular Diversity Preservation International, Basel, Switzerland. This article is an open-access article distributed under the terms and conditions of the Creative Commons Attribution license (http://creativecommons.org/licenses/by/3.0/). 